\title{
Characterization of Early Blight Resistance in Potato Cultivars
}

\author{
Weiya Xue, ${ }^{1}$ Kathleen G. Haynes, ${ }^{2}$ and Xinshun $\mathrm{Qu}^{3, \dagger}$ \\ ${ }^{1}$ Department of Plant Pathology and Environmental Microbiology, The Pennsylvania State University, University Park, PA \\ 16802; ${ }^{2}$ U. S. Department of Agriculture - Agricultural Research Service, Genetic Improvement of Fruits and Vegetables Lab- \\ oratory, Beltsville, MD 20705; and ${ }^{3}$ Department of Plant Pathology and Environmental Microbiology, The Pennsylvania State \\ University, University Park, PA 16802
}

\begin{abstract}
Early blight, caused by the fungus Alternaria solani, is one of the most economically important foliar diseases of potatoes worldwide. In this study, 217 tetraploid old and modern potato cultivars were evaluated for foliar resistance to early blight in field experiments in Pennsylvania in 2016 and 2017. Relative area under the disease progress curve (RAUDPC) was calculated based on visual assessment of foliar disease during the growing season each year. RAUDPC ranged from 0.0090 to 0.7372 in 2016 and from 0.0215 to 0.7889 in 2017, respectively. Significant differences in resistance to A. solani among cultivars were found $(P<0.0001)$. A significant interaction was found between cultivar and environment $(P<0.0001)$. Cluster analysis classified the cultivars into five groups: resistant, moderately resistant, intermediate, moderately

susceptible, and susceptible. Broad-sense heritability for early blight resistance was estimated as 0.89 with a $95 \%$ confidence interval of 0.86 to 0.92 . All cultivars were also evaluated for foliage maturity in separate field trials in 2016 and 2017, and a strong negative correlation between early blight resistance and maturity was found. Maturity-adjusted RAUDPC was calculated by regressing maturity on RAUDPC; predicted values more than two standard deviations greater or less than observed values were used to identify cultivars with greater genetic susceptibility or resistance to early blight, respectively, independent of maturity. Although most resistant and moderately resistant cultivars showed late maturity and most susceptible cultivars showed early maturity, a few exceptions were found.
\end{abstract}

Early blight (EB), caused by the fungus Alternaria solani, is one of the most important and frequent disease of potatoes in all potato growing regions worldwide. A. solani attacks potato leaves, stems, and tubers. The foliar phase is the most common and destructive. Yield losses of potato up to $50 \%$ caused by EB damage have been reported worldwide (Christ and Maczuga 1989; Olanya et al. 2008; Rotem and Feldman 1965; Shtienberg and Fry 1990; Teng and Bissonnette 1985).

Environmental conditions have been reported to play an important role in the development of EB. Favorable temperature $\left(20\right.$ to $\left.26^{\circ} \mathrm{C}\right)$ and long leaf wetness duration or high relative humidity can lead to severe EB epidemics (Holley et al. 1985; Rotem 1994). Therefore, EB can be very destructive where potatoes are grown under irrigation or during times of high moisture (Rotem 1994). In recent years, EB has occurred with increasing frequency in the U.S. and European fields because of climate changes (Edin and Andersson 2014; Runno-Paurson et al. 2015; Tymon et al. 2016).

Currently, cultural practices and fungicide applications are employed for the management of EB due to the lack of strong resistant cultivars. Cultural practices, such as soil amendment, crop rotation, soil fertility, and irrigation, have been shown to have significant effects on EB incidence (Olanya et al. 2008, 2009). Fungicides, including protective and curative fungicides, are the most efficiently way to control EB (Christ and Maczuga 1989; Davidson et al. 2016). However, frequent application of fungicides caused environmental concerns and resulted in fungicide resistance in A. solani (Landschoot et al. 2017; Odilbekov et al. 2016). A. solani insensitivity to QoI fungicides has been increasing (Pasche et al. 2004; Rosenzweig et al. 2008). Frequent use of SDHI fungicides has led to the development of resistance to the fungicide

${ }^{\dagger}$ Corresponding author: Xinshun Qu; E-mail: xsq1@psu.edu

*The $\boldsymbol{e}$-Xtra logo stands for "electronic extra" and indicates that one supplementary table is published online.

Accepted for publication 21 August 2018.

() 2019 The American Phytopathological Society boscalid in A. solani (Gudmestad et al. 2013; Wharton et al. 2012). Once fungicide-resistant isolates of A. solani predominate, controlling the disease with a single chemical fungicide would be impossible.

Genetic resistance offers the most effective means to control EB. Even partial resistance could be useful to reduce the frequency of fungicide applications. However, progress in breeding for EB resistance has been limited by the lack of effective resistance genes in cultivated potato and the linkage of resistance with late foliage maturity. Screening of wild diploid relatives of potato, breeding clones, and limited tetraploid cultivars for resistance to EB has been reported. Wild Solanum species have provided invaluable genetic diversity for disease resistance and other agronomic traits for potato breeders (Jansky 2000; Pavek and Corsini 2001). Jansky and Rouse (2003) screened 32 potato clones from interspecific hybrids for resistance to multiple diseases and found a few EB resistance clones. Jansky et al. (2008) evaluated 156 accessions of 41 wild relatives of potato for EB resistance; the most resistant species were $S$. neorossii, $S$. commersonii, and $S$. tarijense. Various levels of resistance to EB have been reported in tetraploid potato breeding clones and cultivars, but high levels of resistance to EB are rare. Abuley et al. (2018) screened 38 cultivars in Denmark and 12 'slow blighting' cultivars were found. Boiteux et al. (1995) found 22 EB resistant clones among 934 potato breeding clones and cultivars. Generally, common potato cultivars appear much more susceptible to EB than wild species and most common potato cultivars are susceptible to EB. Although several sources of resistance to EB have been found in wild species and clones, extensive evaluation and comparison of large numbers of existing potato cultivars for resistance to EB has rarely been done.

Another major difficulty in obtaining EB resistant materials is the strong correlation observed between resistance and late foliage maturity. Relative maturity is therefore of importance when evaluating potato germplasm for resistance to EB. Late maturity is not a desirable trait in potato cultivars and many of the EB resistant lines are latematuring. Boiteux et al. (1995) screened 934 potato breeding clones and cultivars in Brazil to assess the correlation between EB resistance and foliage maturity; only five of them were identified as having good levels of EB field resistance without being late maturing. Jansky and Rouse (2003) found only two clones with some EB 
Table 1. Mean relative area under the disease progress curve (RAUDPC) of early blight in 2016 and 2017, foliage maturity, and early blight resistance ranking of 217 potato cultivars evaluated in Pennsylvania

\begin{tabular}{|c|c|c|c|c|}
\hline \multirow[b]{2}{*}{ Cultivar } & \multicolumn{2}{|c|}{ Mean RAUDPC } & \multirow[b]{2}{*}{ Maturity ${ }^{\mathbf{a}}$} & \multirow[b]{2}{*}{ Rank $^{\mathbf{b}}$} \\
\hline & 2016 & 2017 & & \\
\hline Alturas & 0.0090 & 0.0215 & 6.0 & 1 \\
\hline Aracy & 0.0300 & 0.0933 & 4.5 & 1 \\
\hline Arran Consul & 0.0168 & 0.0696 & 5.8 & 1 \\
\hline Bannock Russet & 0.0155 & 0.0401 & 6.0 & 1 \\
\hline Barbara & 0.0348 & 0.0778 & 6.0 & 1 \\
\hline Bertita & 0.0121 & 0.0364 & 5.0 & 1 \\
\hline Blue Mac & 0.0090 & 0.0436 & 5.5 & 1 \\
\hline Boone & 0.0316 & 0.0974 & 5.5 & 1 \\
\hline Bzura & 0.0329 & 0.0387 & 5.0 & 1 \\
\hline Calrose & 0.0184 & 0.0563 & 5.5 & 1 \\
\hline Chaposa & 0.0129 & 0.0378 & 6.0 & 1 \\
\hline Defender & 0.0103 & 0.0609 & 5.5 & 1 \\
\hline Desiree & 0.0168 & 0.0609 & 5.5 & 1 \\
\hline Elba & 0.0423 & 0.0835 & 5.5 & 1 \\
\hline Gorbea & 0.0158 & 0.0321 & 5.5 & 1 \\
\hline Greta & 0.0116 & 0.0364 & 6.0 & 1 \\
\hline Ida Rose & 0.0426 & 0.1015 & 5.3 & 1 \\
\hline Iker & 0.0103 & 0.0835 & 5.5 & 1 \\
\hline Kandidat & 0.0268 & 0.0679 & 5.3 & 1 \\
\hline Michoacan & 0.0165 & 0.0586 & 6.0 & 1 \\
\hline Monota & 0.0185 & 0.0853 & 5.3 & 1 \\
\hline Muziranzara & 0.0194 & 0.0470 & 5.5 & 1 \\
\hline Nagore & 0.0332 & 0.0951 & 3.5 & 1 \\
\hline Ontario & 0.0155 & 0.0442 & 6.0 & 1 \\
\hline Ranger Russet & 0.0219 & 0.0864 & 5.0 & 1 \\
\hline Summit Russet & 0.0302 & 0.0609 & 4.5 & 1 \\
\hline Tacna & 0.0215 & 0.0644 & 6.0 & 1 \\
\hline Torridon & 0.0326 & 0.0749 & 6.0 & 1 \\
\hline Ursus & 0.0276 & 0.0616 & 5.8 & 1 \\
\hline All Blue & 0.0258 & 0.1188 & 5.0 & 2 \\
\hline Allegany & 0.0340 & 0.1361 & 5.3 & 2 \\
\hline Alpha & 0.0453 & 0.1778 & 4.3 & 2 \\
\hline Anoka & 0.0434 & 0.1922 & 4.3 & 2 \\
\hline Asun & 0.1282 & 0.1350 & 5.5 & 2 \\
\hline Beacon Chipper & 0.0786 & 0.1501 & 3.8 & 2 \\
\hline Belchip & 0.0644 & 0.2126 & 5.8 & 2 \\
\hline Buckskin & 0.0461 & 0.1136 & 4.8 & 2 \\
\hline Butte & 0.0790 & 0.1367 & 3.8 & 2 \\
\hline Calwhite & 0.0824 & 0.1483 & 5.0 & 2 \\
\hline Carola & 0.0519 & 0.1801 & 5.0 & 2 \\
\hline Chieftain & 0.1817 & 0.1391 & 3.3 & 2 \\
\hline Chinook & 0.0219 & 0.1270 & 4.5 & 2 \\
\hline Chippewa & 0.0492 & 0.1620 & 4.8 & 2 \\
\hline Croft & 0.0226 & 0.2085 & 5.3 & 2 \\
\hline Delta Gold & 0.0184 & 0.1553 & 4.0 & 2 \\
\hline Denali & 0.0606 & 0.1805 & 4.8 & 2 \\
\hline Ella & 0.0658 & 0.1499 & 4.8 & 2 \\
\hline Erie & 0.0416 & 0.1411 & 5.5 & 2 \\
\hline Gem Chip & 0.0532 & 0.1992 & 5.5 & 2 \\
\hline Golden & 0.0681 & 0.1952 & 5.8 & 2 \\
\hline Hampton & 0.0374 & 0.1807 & 4.0 & 2 \\
\hline Katahdin & 0.0352 & 0.2525 & 4.3 & 2 \\
\hline Kennebec & 0.0226 & 0.1946 & 5.3 & 2 \\
\hline Keuka Gold & 0.1298 & 0.1455 & 4.3 & 2 \\
\hline Lamoka & 0.0556 & 0.1738 & 3.3 & 2 \\
\hline Langlade & 0.0348 & 0.1316 & 5.0 & 2 \\
\hline Lemhi & 0.0603 & 0.1825 & 5.5 & 2 \\
\hline \multirow[t]{2}{*}{ Libertas } & 0.0426 & 0.1067 & 5.5 & 2 \\
\hline & & & \multicolumn{2}{|c|}{ (Continued) } \\
\hline
\end{tabular}

a Maturity was recorded as 1 = very early maturity; 2 = early maturity; 3 = medium early maturity; 4 = medium late maturity; 5 = late maturity; and $6=$ very late maturity. The values were the mean of two years' maturity ratings.

${ }^{\mathrm{b}}$ Rank indicates the early blight resistant level: $1=$ resistant; $2=$ moderately resistant; 3 = intermediate resistant; $4=$ moderately susceptible; and $5=$ susceptible.
Table 1. (Continued)

\begin{tabular}{|c|c|c|c|c|}
\hline \multirow[b]{2}{*}{ Cultivar } & \multicolumn{2}{|c|}{ Mean RAUDPC } & \multirow[b]{2}{*}{ Maturity ${ }^{\mathbf{a}}$} & \multirow[b]{2}{*}{$\operatorname{Rank}^{\mathbf{b}}$} \\
\hline & 2016 & 2017 & & \\
\hline LT2 & 0.0474 & 0.1270 & 5.3 & 2 \\
\hline Majestic & 0.0426 & 0.1159 & 5.5 & 2 \\
\hline Marcy & 0.0506 & 0.1796 & 5.0 & 2 \\
\hline Merrimack & 0.0390 & 0.1455 & 5.5 & 2 \\
\hline Mirton Pearl & 0.0613 & 0.1709 & 4.3 & 2 \\
\hline Mohawk & 0.0515 & 0.2357 & 4.8 & 2 \\
\hline Monona & 0.0587 & 0.2460 & 4.3 & 2 \\
\hline Monticello & 0.0987 & 0.0679 & 4.0 & 2 \\
\hline Nampa & 0.0477 & 0.1316 & 6.0 & 2 \\
\hline Norchip & 0.0650 & 0.2640 & 3.3 & 2 \\
\hline Norwis & 0.0858 & 0.1298 & 3.3 & 2 \\
\hline Penn Rose & 0.0642 & 0.1547 & 4.5 & 2 \\
\hline Pennchief & 0.0797 & 0.1431 & 4.8 & 2 \\
\hline Pike & 0.0706 & 0.1420 & 5.0 & 2 \\
\hline Plymouth & 0.0702 & 0.1437 & 3.5 & 2 \\
\hline Prestile & 0.0390 & 0.1727 & 5.5 & 2 \\
\hline Raritan & 0.0632 & 0.1733 & 4.3 & 2 \\
\hline Record & 0.0700 & 0.1249 & 5.5 & 2 \\
\hline Red Maria & 0.0574 & 0.2311 & 4.5 & 2 \\
\hline Rural New Yorker & 0.0408 & 0.1622 & 4.5 & 2 \\
\hline Russet Burbank & 0.0281 & 0.2177 & 4.5 & 2 \\
\hline Russet Katahdin & 0.0323 & 0.1252 & 4.8 & 2 \\
\hline Russet Kennebec & 0.0461 & 0.1489 & 5.3 & 2 \\
\hline Russet Rural & 0.0294 & 0.1547 & 5.3 & 2 \\
\hline Saco & 0.0324 & 0.2172 & 5.0 & 2 \\
\hline Sebago & 0.0287 & 0.1200 & 5.5 & 2 \\
\hline Seneca & 0.0326 & 0.1275 & 4.5 & 2 \\
\hline Serrana & 0.0219 & 0.1142 & 5.5 & 2 \\
\hline Shurchip & 0.0429 & 0.2010 & 4.0 & 2 \\
\hline Stobrawa & 0.0503 & 0.1274 & 4.0 & 2 \\
\hline Strawberry Paw & 0.0416 & 0.1807 & 5.0 & 2 \\
\hline Suncrisp & 0.0369 & 0.1944 & 4.8 & 2 \\
\hline Zarevo & 0.0673 & 0.1385 & 4.8 & 2 \\
\hline Abnaki & 0.0991 & 0.3659 & 3.5 & 3 \\
\hline Acadia Russet & 0.1141 & 0.1742 & 3.8 & 3 \\
\hline Alasclear & 0.0779 & 0.2543 & 5.3 & 3 \\
\hline Amey & 0.0840 & 0.2450 & 5.5 & 3 \\
\hline Arenac & 0.1059 & 0.2103 & 4.5 & 3 \\
\hline Atlantic & 0.2435 & 0.2149 & 4.3 & 3 \\
\hline Avon & 0.0815 & 0.3191 & 4.0 & 3 \\
\hline Bake King & 0.1207 & 0.2731 & 5.5 & 3 \\
\hline Belle Isle & 0.0795 & 0.3711 & 4.8 & 3 \\
\hline Campbell 14 & 0.2223 & 0.2103 & 4.8 & 3 \\
\hline Cariboo & 0.0568 & 0.2334 & 4.3 & 3 \\
\hline Cherokee & 0.1071 & 0.3200 & 3.8 & 3 \\
\hline Donna & 0.1190 & 0.3687 & 3.5 & 3 \\
\hline Eide Russet & 0.0550 & 0.3584 & 3.8 & 3 \\
\hline Emmet & 0.1234 & 0.2274 & 5.0 & 3 \\
\hline Essex & 0.0883 & 0.2846 & 3.3 & 3 \\
\hline Eva & 0.2638 & 0.1646 & 3.8 & 3 \\
\hline Grand Falls & 0.0832 & 0.2594 & 3.8 & 3 \\
\hline Green Mountain & 0.1653 & 0.2334 & 4.0 & 3 \\
\hline Islander & 0.0818 & 0.2709 & 4.8 & 3 \\
\hline Ivory Crisp & 0.0774 & 0.3498 & 3.5 & 3 \\
\hline Kanona & 0.1501 & 0.2404 & 3.8 & 3 \\
\hline Kasota & 0.0844 & 0.3263 & 3.3 & 3 \\
\hline Keswick & 0.0992 & 0.3057 & 2.5 & 3 \\
\hline LaSalle & 0.0592 & 0.2612 & 5.0 & 3 \\
\hline Lehigh & 0.0585 & 0.2198 & 4.5 & 3 \\
\hline Mainechip & 0.0848 & 0.2772 & 4.3 & 3 \\
\hline Navajo & 0.0690 & 0.2389 & 2.5 & 3 \\
\hline Nema Rus & 0.1493 & 0.2083 & 4.5 & 3 \\
\hline New Norchip & 0.0406 & 0.2196 & 5.5 & 3 \\
\hline NorDonna & 0.1507 & 0.2659 & 4.8 & 3 \\
\hline NorValley & 0.0994 & 0.3594 & 4.3 & 3 \\
\hline
\end{tabular}


Table 1. (Continued from previous page)

\begin{tabular}{|c|c|c|c|c|}
\hline \multirow[b]{2}{*}{ Cultivar } & \multicolumn{2}{|c|}{ Mean RAUDPC } & \multirow[b]{2}{*}{ Maturity $^{\mathbf{a}}$} & \multirow[b]{2}{*}{$\operatorname{Rank}^{\mathbf{b}}$} \\
\hline & 2016 & 2017 & & \\
\hline Pontiac & 0.0997 & 0.2981 & 2.8 & 3 \\
\hline Reba & 0.0684 & 0.2196 & 4.5 & 3 \\
\hline Red Kote & 0.0655 & 0.2826 & 5.3 & 3 \\
\hline Red Pontiac & 0.0626 & 0.2451 & 4.5 & 3 \\
\hline Red Skin & 0.0803 & 0.1927 & 4.3 & 3 \\
\hline Reddale & 0.1653 & 0.1512 & 4.8 & 3 \\
\hline Rhine Red & 0.0573 & 0.2407 & 5.3 & 3 \\
\hline Rushmore & 0.1174 & 0.2224 & 4.3 & 3 \\
\hline Russette & 0.0919 & 0.2357 & 5.0 & 3 \\
\hline Shepody & 0.0835 & 0.2314 & 3.3 & 3 \\
\hline Snowden & 0.0448 & 0.3372 & 4.0 & 3 \\
\hline Spartan Pearl & 0.0654 & 0.2848 & 3.5 & 3 \\
\hline Teton & 0.0620 & 0.2964 & 5.5 & 3 \\
\hline Trent & 0.0669 & 0.2728 & 4.8 & 3 \\
\hline Viking & 0.1115 & 0.2825 & 2.3 & 3 \\
\hline Waneta & 0.1295 & 0.2160 & 3.3 & 3 \\
\hline Wauseon & 0.0571 & 0.3656 & 4.5 & 3 \\
\hline White Rose & 0.0926 & 0.2296 & 4.0 & 3 \\
\hline Wyred & 0.1135 & 0.2201 & 3.8 & 3 \\
\hline Alamo & 0.2049 & 0.4288 & 3.3 & 4 \\
\hline BelRus & 0.3352 & 0.3376 & 3.5 & 4 \\
\hline Bounty & 0.2332 & 0.3663 & 2.5 & 4 \\
\hline Calgold & 0.2104 & 0.2728 & 3.5 & 4 \\
\hline Campbell 12 & 0.1238 & 0.3793 & 3.5 & 4 \\
\hline Canoga & 0.1611 & 0.5384 & 3.0 & 4 \\
\hline Cascade M & 0.0611 & 0.4468 & 3.5 & 4 \\
\hline Centennial Russet & 0.1745 & 0.2922 & 3.3 & 4 \\
\hline Climax & 0.1276 & 0.3713 & 3.0 & 4 \\
\hline Coastal Chip & 0.1916 & 0.3379 & 4.0 & 4 \\
\hline Coastal Russet & 0.2949 & 0.3607 & 3.8 & 4 \\
\hline Cobbler & 0.1420 & 0.5481 & 3.8 & 4 \\
\hline DeSota & 0.1110 & 0.4626 & 3.5 & 4 \\
\hline Dorita & 0.3432 & 0.1918 & 3.3 & 4 \\
\hline Early Gem & 0.1631 & 0.3612 & 4.0 & 4 \\
\hline Fontenot & 0.2127 & 0.3664 & 2.5 & 4 \\
\hline Haig & 0.2324 & 0.3473 & 3.3 & 4 \\
\hline Harley Blackwell & 0.2490 & 0.3613 & 4.0 & 4 \\
\hline Hartford & 0.2840 & 0.3381 & 2.8 & 4 \\
\hline High Plains & 0.2178 & 0.4825 & 5.0 & 4 \\
\hline Houma & 0.1585 & 0.4106 & 3.5 & 4 \\
\hline Huron & 0.2288 & 0.4881 & 4.3 & 4 \\
\hline Jacqueline Lee & 0.1840 & 0.3053 & 3.3 & 4 \\
\hline Krantz & 0.1864 & 0.3499 & 3.5 & 4 \\
\hline LaRouge & 0.1509 & 0.4481 & 3.3 & 4 \\
\hline LaSoda & 0.1654 & 0.4405 & 2.5 & 4 \\
\hline Norchief & 0.1238 & 0.3806 & 3.3 & 4 \\
\hline Norgold Russet & 0.2320 & 0.4770 & 2.3 & 4 \\
\hline Norking & 0.1980 & 0.3890 & 2.5 & 4 \\
\hline Ona & 0.2347 & 0.4342 & 2.0 & 4 \\
\hline Onaway & 0.1787 & 0.3919 & 3.0 & 4 \\
\hline Pawnee & 0.2324 & 0.4031 & 3.0 & 4 \\
\hline Penn 71 & 0.2537 & 0.4289 & 3.3 & 4 \\
\hline Penobscot & 0.2169 & 0.3217 & 3.0 & 4 \\
\hline Pioneer & 0.0895 & 0.5019 & 2.8 & 4 \\
\hline Red Burt & 0.1247 & 0.4431 & 4.3 & 4 \\
\hline Red LaSoda & 0.2383 & 0.3172 & 3.3 & 4 \\
\hline Red Warba & 0.2308 & 0.5302 & 1.8 & 4 \\
\hline Reliance & 0.1287 & 0.3823 & 3.5 & 4 \\
\hline Rideau & 0.2012 & 0.4053 & 5.3 & 4 \\
\hline Russet Norkotah & 0.2113 & 0.5113 & 2.5 & 4 \\
\hline Russet Sebago & 0.1804 & 0.5209 & 3.5 & 4 \\
\hline Sable & 0.1642 & 0.3893 & 3.8 & 4 \\
\hline Simco & 0.2524 & 0.4076 & 3.5 & 4 \\
\hline Snowflake & 0.1776 & 0.3842 & 2.3 & 4 \\
\hline Super Red Norland & 0.1360 & 0.4881 & 2.5 & 4 \\
\hline & & & & ntinued) \\
\hline
\end{tabular}

Table 1. (Continued)

\begin{tabular}{|c|c|c|c|c|}
\hline \multirow[b]{2}{*}{ Cultivar } & \multicolumn{2}{|c|}{ Mean RAUDPC } & \multirow[b]{2}{*}{ Maturity $^{\mathbf{a}}$} & \multirow[b]{2}{*}{ Rank $^{\text {b }}$} \\
\hline & 2016 & 2017 & & \\
\hline Vokal & 0.1661 & 0.5496 & 1.8 & 4 \\
\hline Wischip & 0.2348 & 0.4972 & 2.5 & 4 \\
\hline Yukon Gold & 0.1969 & 0.3978 & 1.5 & 4 \\
\hline Agassiz & 0.3157 & 0.4886 & 3.5 & 5 \\
\hline Belmont & 0.5453 & 0.4390 & 3.0 & 5 \\
\hline Bison & 0.4004 & 0.4314 & 3.3 & 5 \\
\hline Caribe & 0.4812 & 0.4377 & 3.3 & 5 \\
\hline Cherry Red & 0.4328 & 0.4541 & 2.3 & 5 \\
\hline Dark Red Norland & 0.4868 & 0.5067 & 2.0 & 5 \\
\hline Early Blue & 0.3353 & 0.4960 & 3.5 & 5 \\
\hline Envol & 0.7372 & 0.7889 & 1.3 & 5 \\
\hline Fundy & 0.4166 & 0.4744 & 2.5 & 5 \\
\hline Goldrus & 0.5498 & 0.4688 & 2.5 & 5 \\
\hline Highlat & 0.3150 & 0.4507 & 3.8 & 5 \\
\hline Hilite Russet & 0.3980 & 0.4974 & 1.3 & 5 \\
\hline Jemseg & 0.3803 & 0.5278 & 2.5 & 5 \\
\hline Menominee & 0.2627 & 0.4242 & 2.3 & 5 \\
\hline Mesaba & 0.3153 & 0.3798 & 3.0 & 5 \\
\hline Nordak & 0.5243 & 0.4670 & 1.5 & 5 \\
\hline Norland & 0.4989 & 0.6542 & 1.8 & 5 \\
\hline Oceania & 0.3553 & 0.4828 & 2.5 & 5 \\
\hline Patrones & 0.3062 & 0.4684 & 2.8 & 5 \\
\hline Peter Wilcox & 0.5211 & 0.4784 & 3.5 & 5 \\
\hline Purple Norland & 0.4445 & 0.4872 & 2.5 & 5 \\
\hline Saginaw Gold & 0.3291 & 0.4594 & 3.8 & 5 \\
\hline Somerset & 0.2625 & 0.3680 & 4.0 & 5 \\
\hline Superior & 0.2796 & 0.5144 & 2.3 & 5 \\
\hline Warba & 0.3820 & 0.4724 & 3.3 & 5 \\
\hline York & 0.2582 & 0.4950 & 2.8 & 5 \\
\hline
\end{tabular}

resistance without late maturity in the 32 interspecific Solanum hybrid clones they screened.

Heritability is an important parameter for breeding and selection of disease resistance in crops since it estimates the total genetic component of resistance as a proportion of the phenotypic resistance (Nyquist 1991). Broad-sense heritability of EB resistance in potato has been estimated in previous studies at the tetraploid level (Haynes and Qu 2016). EB resistance has shown high narrow-sense heritability, ranging from 0.64 to 0.85 , in diploid potato populations (Christ and Haynes 2001; Herriott et al. 1986; Ortiz et al. 1993), suggesting that most of the genetic variance is of an additive nature. The high estimates of both broad-sense and narrow-sense heritability suggest that relatively few genes are involved in EB resistance and that once resistant germplasm is developed, resistance should be fairly stable across environments. Thus, the biggest impediment to developing cultivars with high levels of resistance to EB is the linkage to late maturity.

There are hundreds of old and modern tetraploid potato cultivars in the U.S., but the susceptibility of most of these cultivars to EB is unknown. The objectives of this study were to (i) identify sources of resistance to EB in potato by screening a large number of existing potato cultivars, (ii) dissect inheritance of EB resistance, and (iii) determine the association between EB resistance and foliage maturity. Here we report that EB resistance exists in this collection of potato cultivars and it is possible to breed new resistant potato cultivars without late maturity.

\section{Materials and Methods}

Plant materials. The USDA ARS-Beltsville Potato Breeding Program maintains a tetraploid potato collection of 217 cultivars (Table 1). Among the 217 cultivars, 171 cultivars originated from the U.S., nine from Canada, 26 from Europe, and 11 from South America. These cultivars were planted in Presque Isle, Maine, each year. After harvest, tubers of all cultivars were shipped to Pennsylvania for field disease and maturity evaluations. 
Field disease evaluation experiment. All field experiments were conducted at The Pennsylvania State University Russell E. Larson Agricultural Research Center in Pennsylvania Furnace, PA. Cultivars were planted on 15 May 2016 and 20 May 2017 in a randomized complete block design with two replications. Plots were $1.21 \mathrm{~m}$ long with five seed pieces planted $30 \mathrm{~cm}$ apart in each plot and $1.21-\mathrm{m}$ breaks between plots within a row. Each treatment row had an adjacent row of an EB susceptible cultivar Dark Red Norland as a spreader row. Standard crop management practices were followed throughout the growing season, with the exception that no fungicides were sprayed for EB. Three isolates of $A$. solani were used as inoculum. These three isolates were isolated from naturally infected leaves of potatoes found in Pennsylvania in previous years, and stored on silicone gel at $4{ }^{\circ} \mathrm{C}$. Prior to inoculation, the isolates were grown on V8 agar medium in Petri dishes for about 7 days to induce sporulation. The conidia were collected by rinsing the plates with distilled water and the suspensions were mixed and adjusted to a concentration of $1.5 \times 10^{4}$ per ml. Spreader rows were sprayinoculated with a mixture of the three isolates on 14 July 2016 and 13 July 2017, to promote a uniform spread of the pathogen to all treatment plots, respectively. Late blight, another foliar disease of potato caused by Phytophthora infestans, was not observed in the fields either year. EB disease ratings were determined by visually assessing each plot and estimating the percentage of diseased foliage on a 0 to $100 \%$ scale. In 2016, assessments were made on 26 July and 1, 5, 10 , 14, 18, 22, and 26 August. In 2017, assessments were made on 25 and 31 July and 6, 11, 16, and 21 August. Disease data were expressed as area under the disease progress curve (AUDPC) (Shaner and Finney 1977) for each plot. Weather data were collected from a weather station near the trial fields.

Potato maturity assessment. Separate field trials to evaluate potato foliage maturity were conducted at The Pennsylvania State University Russell E. Larson Agricultural Research Center in 2016 and 2017. Potato cultivars were planted on 14 May 2016 and 16 May 2017 , respectively. The experimental design was a randomized complete block with two replications. The plots were $1.82 \mathrm{~m}$ long with eight seed pieces planted in each plot and $1.52 \mathrm{~m}$ breaks between plots within a row. Standard crop management practices were followed and insect pests and late and early blights were controlled by standard chemical sprays throughout the growing season. On 26 August 2016 and 30 August 2017, leaf senescence (foliage maturity) per plot was visually assessed. Cultivar Dark Red Norland was used as an early maturity check cultivar, rated as 2 , and other cultivars were compared with Dark Red Norland to rate the maturity. The maturity was scored into six levels: 1 = very early maturity; 2 = early maturity; 3 = medium early maturity; 4 = medium late maturity; $5=$ late maturity; and $6=$ very late maturity. The values of maturity each year were the mean of two replicates. The final values of maturity were the mean of two years.

Statistical analysis. Relative AUDPC (RAUDPC) was calculated by dividing the AUDPC by 100 times the duration of disease assessment days (Fry 1978). The RAUDPC data were square root transformed for the analysis of variance. Due to homogeneous error variances, the data were subsequently combined over years for analysis with the software STAR (IRRI 2014). The correlation of RAUDPC between the two years was done in R statistical software by the spearman method (R Core Team 2018). RAUDPC comparison between the two years was done by the Wilcoxon signed rank test with continuity correction in $\mathrm{R}$ statistical software ( $\mathrm{R}$ Core Team 2018).

The broad-sense heritability estimate for EB resistance was estimated from the combined square root transformed RAUDPC data over years as $H^{2}=\sigma_{\mathrm{c}}^{2} /\left(\sigma_{\mathrm{c}}^{2+} \sigma_{\mathrm{yc}}^{2} / \mathrm{y}+\sigma_{\mathrm{e}}^{2} / \mathrm{ry}\right)$, where $\sigma_{\mathrm{c}}^{2}=$ cultivar variance, $\sigma_{\mathrm{yc}}^{2}=$ year $\times$ cultivar variance, $\sigma_{\mathrm{e}}^{2}=$ error variance, $r=$ number of replications, and $\mathrm{y}=$ number of years. The broad-sense heritability was calculated by the SOMMER R package with Linear Mixed Model (Covarrubias-Pazaran 2016). A 95\% confidence interval about this estimate was also obtained (Knapp et al. 1985).

Maturity-adjusted RAUDPC values were calculated from the linear regression of average maturity by year on average RAUDPC by year with the regression procedure in SAS, version 9.2 using the $r$ (analysis of residuals) and p (predicted values) options in the model statement. Studentized residuals more than two standard deviations in the positive direction indicated that the predicted value was significantly less than the observed value, and therefore that cultivar was significantly more susceptible to EB than expected based on its maturity. Conversely, studentized residuals more than two standard deviations in the negative direction indicated that the predicted value was significantly more than the observed value, and therefore that cultivar was significantly more resistant to EB than expected based on its maturity. Thus, it was possible to distinguish genetic resistance or susceptibility from the effect of maturity.

RAUDPC were transformed into RaRAUDPC according to Yuen and Forbes (2009). In brief, all the RAUDPC were divided by the RAUDPC of a standard cultivar Atlantic to get the RaRAUDPC. The square root value of RaRAUDPC showed a normal distribution in each year. The square root RaAUDPC data from two years were used as two variables (one for each year) to rank the EB resistance with a cluster analysis method. The factoextra $\mathrm{R}$ package (https:// cran.r-project.org/web/packages/factoextra/index.html) was used for the cluster analysis. The optimal number of clusters was computed

Table 3. Analysis of variance of square root transformed relative area under the disease progress curve (RAUDPC) of early blight resistance of 217 potato cultivars evaluated in 2016 and 2017 in Pennsylvania

\begin{tabular}{lrcr}
\hline Source & DF & Mean square & $\boldsymbol{P r}(>\boldsymbol{F})$ \\
\hline Year & 1 & 5.8481 & 0.0098 \\
Block (year) & 2 & 0.0584 & $<0.0001$ \\
Cultivar & 216 & 0.0861 & $<0.0001$ \\
Year $\times$ cultivar & 216 & 0.0095 & $<0.0001$ \\
Error & 432 & 0.0047 & \\
Total & 867 & & \\
\hline
\end{tabular}

Table 2. Summary of monthly weather conditions during potato growing seasons in 2016 and 2017 in Pennsylvania Furnace, Pennsylvania

\begin{tabular}{|c|c|c|c|c|c|c|c|c|}
\hline & \multicolumn{4}{|c|}{2016} & \multicolumn{4}{|c|}{2017} \\
\hline & May & June & July & August & May & June & July & $\overline{\text { August }}$ \\
\hline Tavg $\left({ }^{\circ} \mathrm{C}\right)^{\mathrm{a}}$ & 14.4 & 20.2 & 23.0 & 22.9 & 14.0 & 19.7 & 21.9 & 19.5 \\
\hline $\operatorname{Tmax}\left({ }^{\circ} \mathrm{C}\right)^{\mathrm{b}}$ & 19.5 & 25.6 & 29.4 & 28.5 & 18.9 & 25.3 & 27.0 & 24.9 \\
\hline $\operatorname{Tmin}\left({ }^{\circ} \mathrm{C}\right)^{\mathrm{c}}$ & 9.3 & 14.2 & 17.1 & 18.0 & 8.8 & 14.0 & 17.1 & 14.3 \\
\hline Precipitation $(\mathrm{mm})^{\mathrm{d}}$ & 59.4 & 63.5 & 83.6 & 105.2 & 127.0 & 105.2 & 156.5 & 86.1 \\
\hline Leaf wetness $(\mathrm{h})^{\mathrm{e}}$ & 203.0 & 116.0 & 119.0 & 105.0 & 155.0 & 71.0 & 105.0 & 115.0 \\
\hline $\mathrm{RH}>90 \%(\mathrm{~h})^{\mathrm{f}}$ & 314.0 & 217.0 & 257.0 & 325.0 & 258.0 & 244.0 & 310.0 & 382.0 \\
\hline
\end{tabular}

a Monthly average temperature.

${ }^{\mathrm{b}}$ Monthly average maximum temperature.

${ }^{c}$ Monthly average minimum temperature.

${ }^{\mathrm{d}}$ Monthly total millimeters of precipitation.

${ }^{\mathrm{e}}$ Monthly total hours of leaf wetness.

${ }^{\mathrm{f}}$ Monthly total hours of relative humidity $>90 \%$. 
by the fviz_nbclust function with k-means method, then the k-means and fviz_cluster functions were applied to compute and visualize k-means clustering (Kassambara 2017).

\section{Results}

Environments. Weather conditions during the 2016 and 2017 growing seasons are summarized in Table 2. The temperature in 2016 was higher than that in 2017, particularly later in the growing season. The weather was drier during EB developmental stage in August in 2016 than that in 2017, as reflected by the lower relative humidity and duration of leaf wetness in 2016. The frequency distributions of RAUDPC for the cultivars likewise reveal that RAUDPC was less severe in 2016 than 2017 (Fig. 1). There were significant differences in average RAUDPC between 2016 and 2017 ( 0.1347 versus $0.2670, P=0.0098$, Table 3 ). The mean RAUDPC of each cultivar ranged from 0.0090 to 0.7372 and from 0.0215 to 0.7889 in 2016 and 2017, respectively (Table 1 and Fig. 1). The rate of EB development between the two years was compared (Fig. 2). The average disease severity of all cultivars in 2017 developed much faster than that in 2016. This result suggested that the environment of 2017 was more suitable for EB infection than that of 2016.

Distribution of EB resistance among potato cultivars. There were significant differences among cultivars for RAUDPC $(P<$ 0.0001 ) (Table 3). None of the cultivars was fully resistant to EB because all cultivars exhibited some level of susceptibility (Table 1). The distribution of RAUDPC showed that EB resistance is a continuous quantitative trait each year (Fig. 1).

Interaction between environment $x$ cultivar. Significant interaction was found between cultivar and environment $(P<0.0001$, Table 3). Cultivars such as Monticello, Norwis, Asun, Butte, Chieftain, Penn Chief, Keuka Gold, Calwhite, Beacon Chipper, Reddale, Eva, Acadia Russet, Dorita, and NemaRus showed strong interaction with the environment, the RAUDPC of these cultivars trending to the middle among all the cultivars in 2016, but trending to the resistant side in 2017 (Table 1 and Fig. 1). Cultivars such as Croft, Russet
Burbank, New Norchip, Red Maria, Cariboo, Rhine Red, Monona, Katahdin, Spartan Pearl, Teton, and Snowden also showed strong interaction with the environment, the RAUDPC of these cultivars trending to the resistant side in 2016, but trending to the middle in 2017.

Although there was a strong interaction between cultivar and environment, the RAUDPC between the two years were highly correlated $(r=0.82$, Fig. 3 ). In general, most of the cultivars that were resistant to EB in 2016 were resistant in 2017, and most of the cultivars that were susceptible to EB in 2016 were susceptible in 2017.

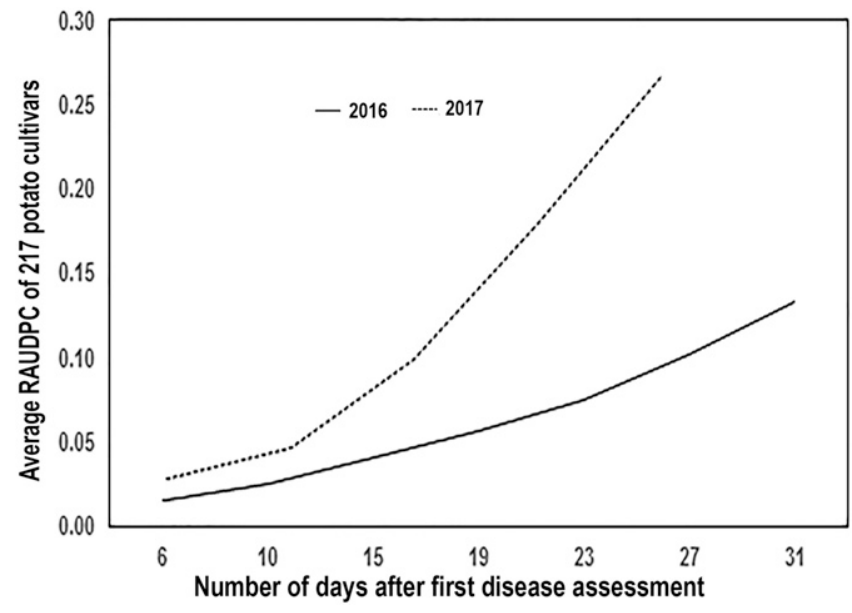

Fig. 2. Comparison of rate of early blight disease development between 2016 and 2017. The horizontal axis indicates the number of days after first disease assessment; the vertical axis indicates average relative area under the disease progress curve (RAUDPC) of 217 potato cultivars in 2016 and 2017 in Pennsylvania.

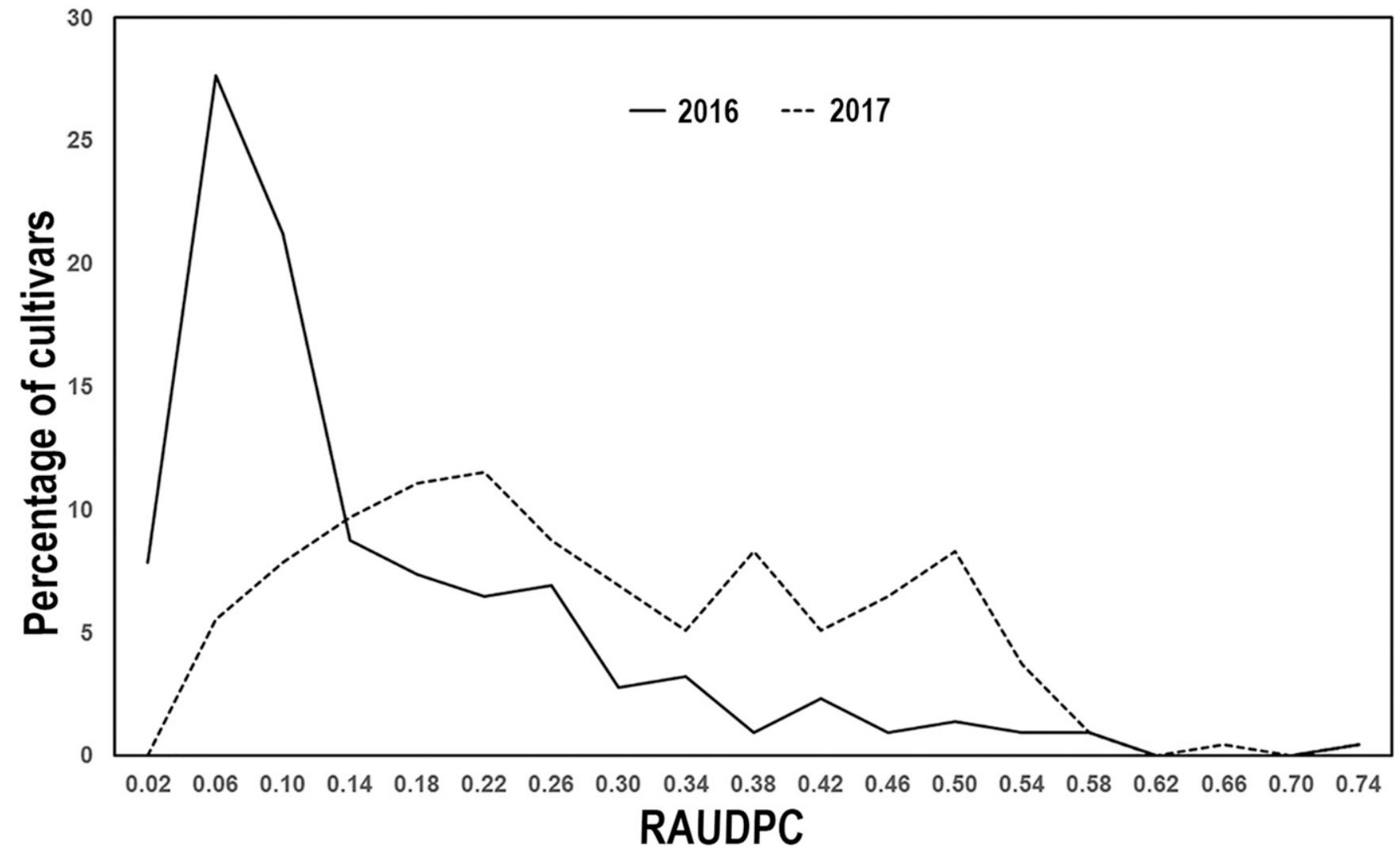

Fig. 1. The frequency distribution of relative area under the disease progress curve (RAUDPC) of early blight among 217 potato cultivars in 2016 and 2017 in Pennsylvania. 
Heritability of EB resistance in potato cultivars. Broad-sense heritability for EB resistance, as measured by combined two years' RAUDPC, was 0.89 with a $95 \%$ confidence interval of 0.86 and 0.92 . Cultivar $\times$ environmental variation accounted for only $7.2 \%$ of the total variation.

Ranking EB resistance in potato cultivars. Square root values of RaRAUDPC over two years were used to cluster the cultivars for their EB susceptibility. All 217 cultivars were clustered into five groups (Fig. 4 and Table 1). Group 1 included 29 cultivars classified as resistant, group 2 included 62 cultivars as moderately resistant, group 3 included 51 cultivars as intermediate resistant, group 4 included 49 cultivars as moderately susceptible, and group 5 included 26 cultivars as susceptible.
Correlation between potato maturity and $\mathrm{EB}$ resistance. The correlation coefficient between plant maturity and EB resistance was -0.69 and -0.77 in 2016 and 2017, respectively (Fig. 5). Linear regression was used to separate true genetic resistance from maturity. Maturity was regressed on RAUDPC each year. The difference between observed RAUDPC and predicted RAUDPC for each cultivar was calculated (i.e., how far away from the linear regression line each cultivar was). Differences more than two standard deviations were significant at $P=0.05$ : when this difference was positive, the observed RAUDPC was greater than the predicted (i.e., the observed value of RAUDPC was above the regression line), indicating that the cultivar was significantly more susceptible than maturity alone would explain; when this difference was negative, the observed

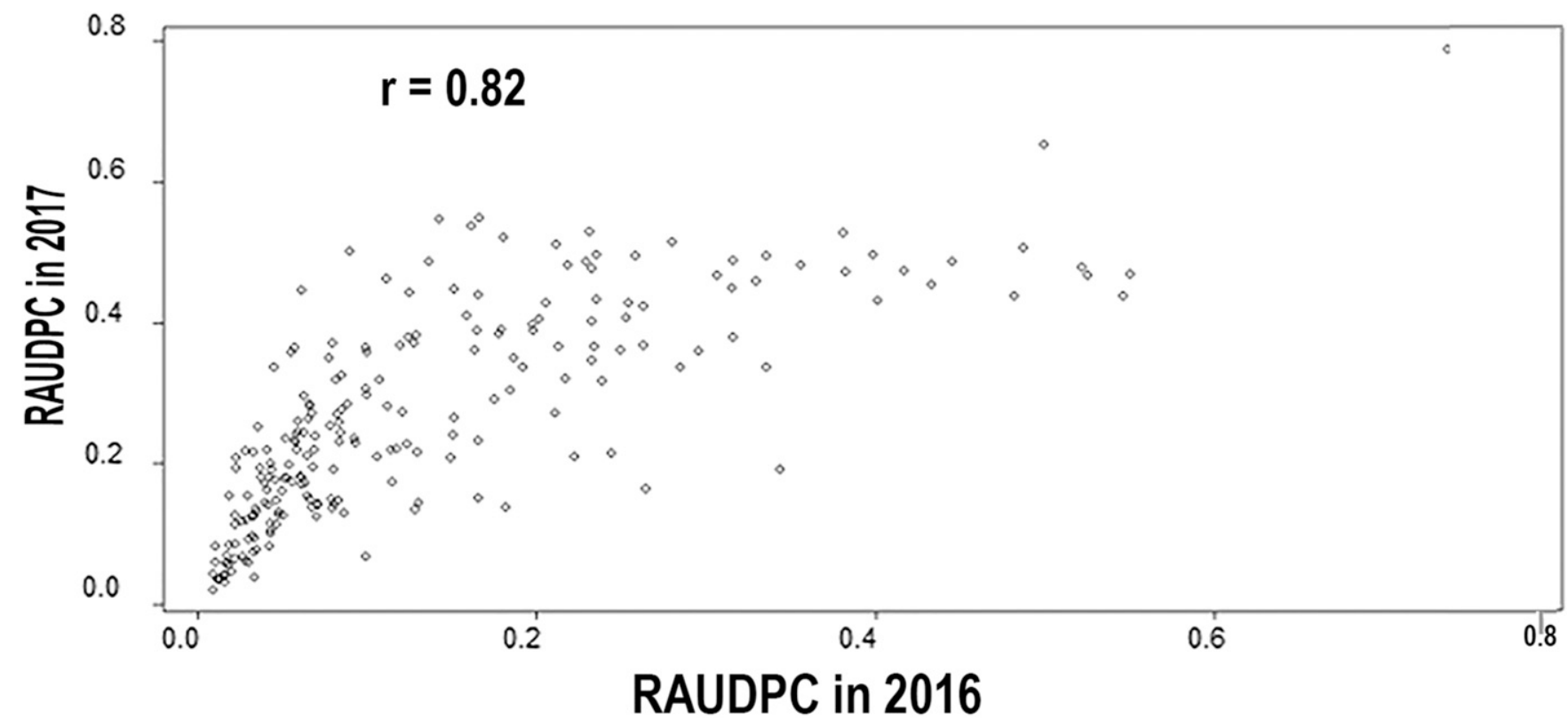

Fig. 3. Scatter plots of relative area under the disease progress curve (RAUDPC) of early blight of 217 potato cultivars between 2016 and 2017 in Pennsylvania. The $r$ value is Spearman's rank correlation coefficient.

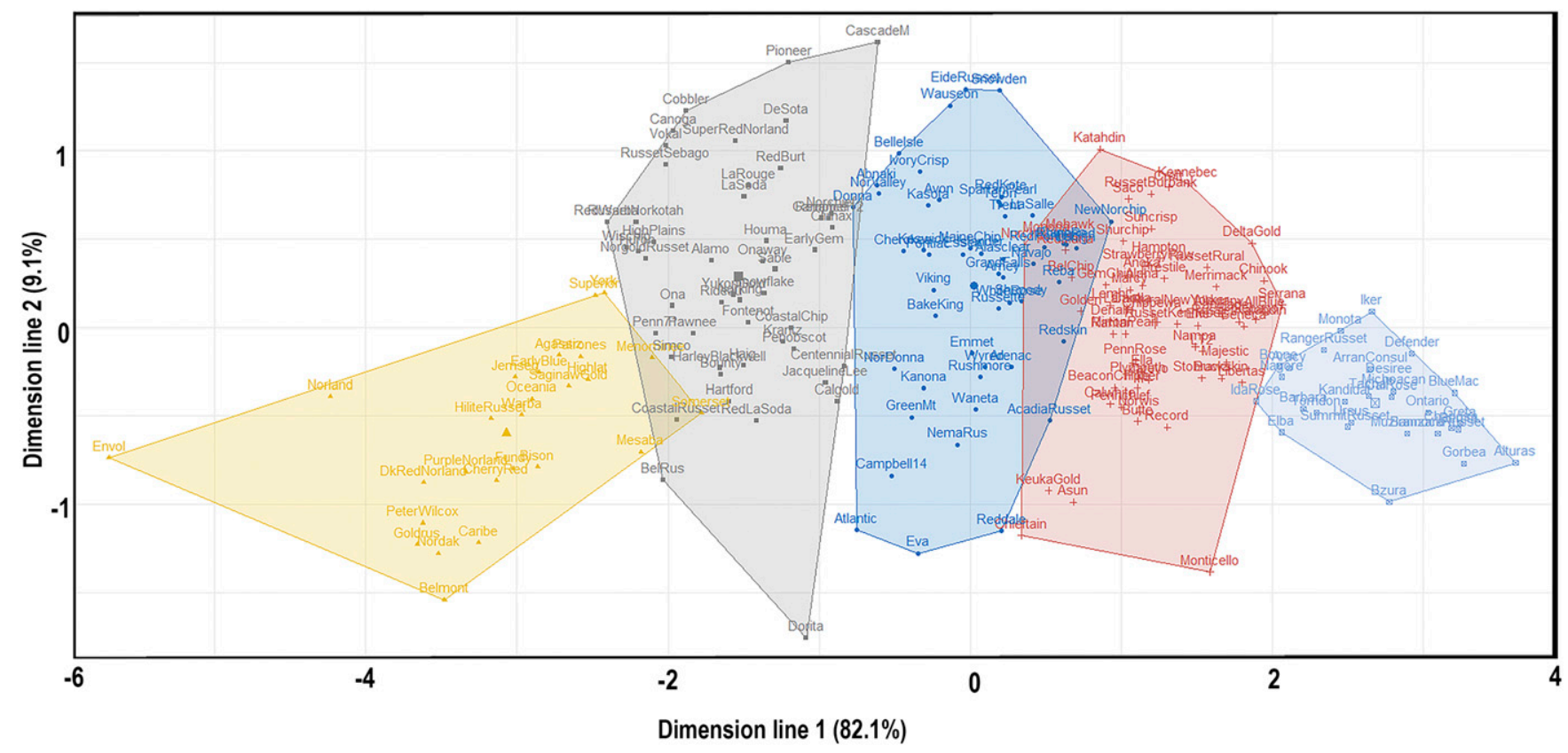

Fig. 4. Cluster analysis of early blight resistant among 217 potato cultivars. Different colors indicate different cluster groups from susceptible (left) to resistant (right). 
RAUDPC was less than predicted (i.e., the observed value of RAUDPC was below the regression line), indicating that the cultivar was significantly more resistant than maturity alone would explain. There was a genetic component of susceptibility independent of maturity for Belmont, Bison, Caribe, Early Blue, Envol, Goldrus, Highlat, Peter Wilcox, Purple Norland, and Rideau in 2016, and for Coastal Chip, Cobbler, Envol, Rideau, and Warba in 2017 (Supplementary Table S1). There was a genetic component to resistance independent of maturity for Navajo and Suncrisp in 2016, and Chieftain, Gorbea, Monticello, Nagore, and Norwis in 2017.

\section{Discussion}

In this study, 217 potato cultivars were evaluated for EB resistance in field experiments. Although none of the cultivars was immune to EB, many resistant and moderately resistant cultivars were identified. Among resistant and moderately resistant cultivars, six cultivars including Nagore, Plymouth, Norwis, Lamoka, Chieftain, and Norchip were not late maturing. The only commercially significant cultivars in the U.S. among these six are Chieftain and Lamoka.

Weather conditions were different between the two years of this study. EB developed much faster and was more severe in 2017, due primarily to more moist environmental conditions. It has been reported that Alternaria sporulates best at about $26.6^{\circ} \mathrm{C}$ when abundant moisture is present (Rotem 1994). Although it was warmer in 2016 than in 2017, leaf wetness time in August of 2017 and relative humidity (>90\%) hours were longer than that in August of 2016, and it was during this period that the disease developed quickly. We speculate that this difference in moisture levels between the two years, rather than temperature differences, caused EB to be more prevalent in 2017. In a previous study, Holley et al. (1985) modeled EB infection to leaf wetness duration and air temperature and concluded that leaf wetness accounted for 85 to $89 \%$ of the variability in infection rate. Our result confirmed their conclusion, suggesting that leaf wetness duration and high relative humidity played important roles in EB infection.

Although a large number of wild potato species/accessions and breeding clones has been evaluated for EB resistance in previous studies, only a limited number of potato cultivars has been assessed for EB resistance. In this study, we evaluated a collection of 217 old and modern potato cultivars. Most of these cultivars were originally from the U.S. and some were from other continents. Significant differences in resistance to EB among cultivars were found. This result is in agreement with previous research (Abuley et al. 2018; Boiteux et al. 1995; Christ et al. 2002; Duarte et al. 2014; Herriott et al. 1986). Although EB resistance has been identified in wild species (Jansky et al. 2008), only a moderate level of resistance has been found in tetraploid breeding lines and cultivars (Abuley et al. 2018; Duarte et al. 2014). Cultivar Aracy was used as a resistant standard in previous studies (Boiteux et al. 1995; Duarte et al. 2014). In our cluster analysis, Aracy and another 28 cultivars were found in the EB resistant cluster and 62 cultivars were found to be moderately resistant. Some of these resistant/moderately resistant cultivars are considered old cultivars and are currently not grown by growers due to the lack of other attractive traits. Some were developed outside the U.S. However, these cultivars are maintained in potato breeding programs and at the Potato Genebank and could be used as genetic resources of $\mathrm{EB}$ resistance.

In this study, the estimate of broad-sense heritability for RAUDPC was high (0.89) for EB resistance. In previous studies (Christ and Haynes 2001; Christ et al. 2002; Haynes and Qu 2016), broadsense heritability estimates of EB resistance were also high, ranging from 0.73 to 0.91 in other potato populations. The results in all these studies are similar with our current results and indicate that the underlying genetic basis of EB resistance behaves similarly in diploid (Christ and Haynes 2001), interploidy (Christ et al. 2002), and aneuploid (Haynes and Qu 2016) populations involving different Solanum species. Since the cultivars in this study came from different regions and different historical periods, their genetic background should not be very narrow. With quantitative resistance and high broad-sense heritability, resistant cultivars identified in this study have great potential for use as a source of genetic resistance to the disease.

No major EB resistant gene has been identified in potatoes. In this study, no cultivar showed vertical resistance. This is in agreement with previous research (Abuley et al. 2018; Boiteux et al. 1995; Christ and Haynes 2001; Duarte et al. 2014; Haynes and Qu 2016; Herriott et al. 1986). EB resistance among 217 potato cultivars showed a continuous distribution from low to high. This result suggests that $\mathrm{EB}$ resistance is a quantitative trait that is controlled polygenically. A mapping study for EB resistance in a diploid potato population identified five EB resistance quantitative trait loci (QTLs), explaining 62\% of the total phenotypic variation for resistance (Zhang 2004), confirming the presence of minor genes for EB resistance in potato.

Although the environment $x$ cultivar interaction of EB resistance was significant in this study, it accounted for a small proportion of the total experimental variation and did not appear to affect the ranking of the cultivars for resistance or susceptibility. However, environment did have an influence on the genetic component of both resistance and susceptibility, as indicated by the fact that there was little overlap between cultivars showing a genetic component of resistance or susceptibility in 2016 and 2017. Envol and Rideau were the only cultivars with a significant genetic component of susceptibility both years and no cultivar had a significant genetic component of resistance both years. Cultivars with some genetic components of resistance could be crossed with those cultivars whose resistance was correlated with maturity, but the path to developing early maturing, EB resistant cultivars is likely to be slow, since there is no evidence for dominant-type resistance in this germplasm. At the very least, cultivars that have a genetic component of susceptibility should not be utilized in the breeding program. The use of linear regression to separate genetic components of resistance from maturity-related resistance has been used with other diseases in potatoes (Simko and Haynes 2017).
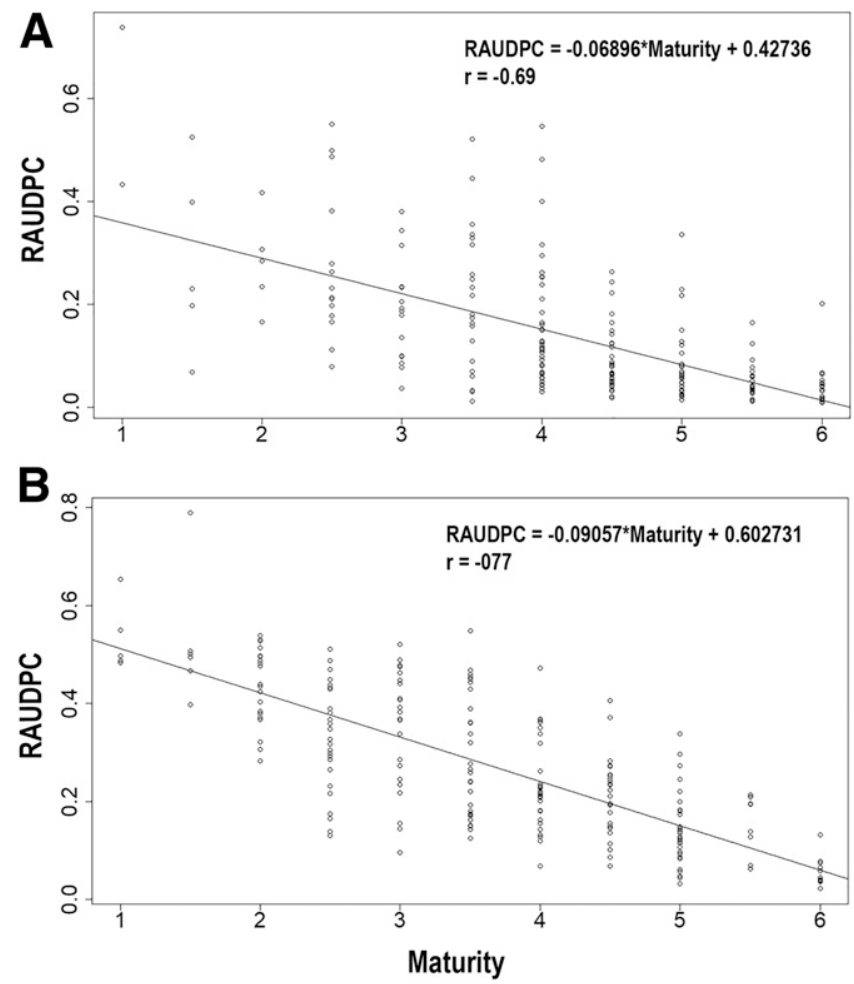

Fig. 5. Scatter plots of the mean relative area under the disease progress curve (RAUDPC) of early blight against maturity among 217 potato cultivars in 2016 (A) and 2017 (B) in Pennsylvania. The $r$ value is the Spearman's rank correlation coefficient. 
In previous studies, EB resistance in potato was associated with late foliage maturity (Abuley et al. 2018; Boiteux et al. 1995; Zhang 2004). Our result confirmed this phenomenon. The strong association between $\mathrm{EB}$ resistance and late maturity may be due to either close linkage or to pleiotropic effects of genes/QTLs. Two of five EB resistance QTLs identified by Zhang (2004) in a diploid potato population shared the same chromosome region with foliage maturity QTLs. The other three EB resistance QTLs, which did not have an effect on foliage maturity, explained $33.1 \%$ of the total phenotypic variation for resistance. In that mapping population, about half the genotypic variation for EB resistance was linked to maturity and about half the genotypic variation for EB resistance was not linked to maturity (Zhang 2004). With the lack of a fine mapping study of EB resistance, it is hard to address this phenomenon genetically. However, variation in EB resistance occurs among cultivars of the same maturity class, indicating that differences in resistance are not always or exclusively an artifact of maturity effects. Jansky and Rouse (2003) found two clones with some EB resistance without late maturity among 32 interspecific Solanum hybrid clones. Boiteux et al. (1995) identified five clones with EB resistance without late maturity from 945 cultivars and clones. In the present study, although potato maturity was highly negatively correlated with EB resistance, there are still a few exceptions, such as resistant cultivar Nagore without late maturity. On the other hand, cultivars such as Somerset, Peter Wilcox, Highlat, and Saginaw Gold are highly susceptibility but medium late maturing.

Area under the disease-progress curve (AUDPC) is considered one of the main criteria to measure resistance in potato to foliar diseases such as late blight and EB. However, AUDPC is affected by many factors other than the level of host resistance and is only applicable within a single experiment. RAUDPC was proposed as a more stable measure of cultivar performance (Fry 1978), but it is also subject to variation from factors that are experiment specific (Yuen and Forbes 2009). RaRAUDPC was presented as an alternative disease measure that could be used for classifying potato genotypes for susceptibility across experiments using potato late blight as an example (Yuen and Forbes 2009). To minimize the possibility of drawing erroneous conclusions on classification of EB resistance of cultivars, Abuley et al. (2018) performed cluster analysis based on six variables, and classified 38 cultivars into four clusters but there was no resistant control in their study. Other researchers used Aracy as a resistant standard to define the resistant cultivars (Boiteux et al. 1995; Duarte et al. 2014). When we classified the cultivars for EB resistance, we adopted the RaRAUDPC approach as a measure of EB resistance. We chose the intermediate resistant cultivar Atlantic as a reference genotype. The designation of resistant to susceptible clusters, and the assignment of cultivars to one of these clusters in this study will be a useful reference for other researchers and potato breeders. Genome-wide association studies are underway to identify QTLs linked to EB resistance and foliage maturity in this collection of potato cultivars.

\section{Literature Cited}

Abuley, I. K., Nielsen, B. J., and Labouriau, R. 2018. Resistance status of cultivated potatoes to early blight (Alternaria solani) in Denmark. Plant Pathol. 67:315-326.

Boiteux, L. S., Reifschneider, F. J. B., Fonseca, M. E. N., and Buso, J. A. 1995. Search for sources of early blight (Alternaria-Solani) field-resistance not associated with vegetative late maturity in tetraploid potato germplasm. Euphytica 83:63-70.

Christ, B. J., and Haynes, K. G. 2001. Inheritance of resistance to early blight disease in a diploid potato population. Plant Breed. 120:169-172.

Christ, B. J., Haynes, K. G., and Vinyard, B. T. 2002. Inheritance of early blight resistance from open-pollinated $4 \mathrm{x}-2 \mathrm{x}$ potato hybrids. Am. J. Potato Res. 79: 403-410.

Christ, B. J., and Maczuga, S. A. 1989. The effect of fungicide schedules and inoculum levels on early blight severity and yield of potato. Plant Dis. 73: 695-698.

Covarrubias-Pazaran, G. 2016. Genome-assisted prediction of quantitative traits using the R package sommer. PLoS One 11:e0156744.

Davidson, R. D., Houser, A. J., and Haslar, R. 2016. Control of early blight in the San Luis Valley, Colorado. Am. J. Potato Res. 93:43-49.
Duarte, H. S. S., Zambolim, L., Rodrigues, F. A., Paul, P. A., Pádua, J. G., Ribeiro Júnior, J. I., Júnior, A. F. N., and Rosado, A. W. C. 2014. Field resistance of potato cultivars to foliar early blight and its relationship with foliage maturity and tuber skin types. Trop. Plant Pathol. 39:294-306.

Edin, E., and Andersson, B. 2014. The early blight situation in Sweden - species abundance and strobilurin sensitivity. Pages 83-84 in: Proceedings of the 14th EuroBlight Workshop, Limassol, Cyprus. H. T. A. M. Schepers, ed. Wageningen University, Wageningen, The Netherlands.

Fry, W. E. 1978. Quantification of general resistance of potato cultivars and fungicide effects for integrated control of potato late blight. Phytopathology 68:1650-1655.

Gudmestad, N. C., Arabiat, S., Miller, J. S., and Pasche, J. S. 2013. Prevalence and impact of SDHI fungicide resistance in Alternaria solani. Plant Dis. 97: 952-960.

Haynes, K. G., and Qu, X. S. 2016. Late blight and early blight resistance from Solanum hougasii introgressed into Solanum tuberosum. Am. J. Potato Res. 93:86-95.

Herriott, A. B., Haynes, F. L., and Shoemaker, P. B. 1986. The heritability of resistance to early blight in diploid potatoes (Solanum tuberosum, subsp. Phureja and Stenotomum). Am. Potato J. 63:229-232.

Holley, J. D., Hall, R., and Hofstra, G. 1985. Effects of cultivar resistance, leaf wetness duration and temperature on rate of development of potato early blight. Can. J. Plant Sci. 65:179-184.

IRRI. 2014. STAR, version 2.0.1. Biometrics and Breeding Informatics, PBGB Division, International Rice Research Insititute, Los Baños, Laguna, Philippines.

Jansky, S. H. 2000. Breeding for disease resistance in potato. Plant Breed. Rev. 19: 69-155.

Jansky, S. H., and Rouse, D. I. 2003. Multiple disease resistance in interspecific hybrids of potato. Plant Dis. 87:266-272.

Jansky, S. H., Simon, R., and Spooner, D. M. 2008. A test of taxonomic predictivity: Resistance to early blight in wild relatives of cultivated potato Phytopathology 98:680-687.

Kassambara, A. 2017. Practical guide to cluster analysis in R. CreateSpace Independent Publishing Platform. STHDA, New York.

Knapp, S. J., Stroup, W. W., and Ross, W. M. 1985. Exact confidence intervals for heritability on a progeny mean basis. Crop Sci. 25:192-194.

Landschoot, S., Vandecasteele, M., Carrette, J., De Baets, B., Hofte, M. Audenaert, K., and Haesaert, G. 2017. Assessing the Belgian potato Alternaria population for sensitivity to fungicides with diverse modes of action. Eur. J. Plant Pathol. 148:657-672.

Nyquist, W. E. 1991. Estimation of heritability and prediction of selection response in plant-populations. Crit. Rev. Plant Sci. 10:235-322.

Odilbekov, F., Edin, E., Garkava-Gustavsson, L., Hovmalm, H. P., and Liljeroth, E. 2016. Genetic diversity and occurrence of the F129L substitutions among isolates of Alternaria solani in south-eastern Sweden. Hereditas 153:10.

Olanya, O. M., Honeycutt, C. W., Larkin, R. P., Griffin, T. S., He, Z. Q., and Halloran, J. M. 2008. Enhancing potato system sustainability: Microclimate, early blight and late blight potential. Phytopathology 98:S115.

Olanya, O. M., Honeycutt, C. W., Larkin, R. P., Griffin, T. S., He, Z. Q., and Halloran, J. M. 2009. The effect of cropping systems and irrigation management on development of potato early blight. J. Gen. Plant Pathol. 75: 267-275.

Ortiz, R., Martin, C., Iwanaga, M., and Torres, H. 1993. Inheritance of early blight resistance in diploid potatoes. Euphytica 71:15-19.

Pasche, J. S., Wharam, C. M., and Gudmestad, N. C. 2004. Shift in sensitivity of Alternaria solani in response to Q(o)I fungicides. Plant Dis. 88:181-187.

Pavek, J. J., and Corsini, D. L. 2001. Utilization of potato genetic resources in variety development. Am. J. Potato Res. 78:433-441.

R Core Team. 2018. R: A language and environment for statistical computing. $\mathrm{R}$ Foundation for Statistical Computing, Vienna, Austria. https://www.R-project. org/.

Rosenzweig, N., Atallah, Z. K., Olaya, G., and Stevenson, W. R. 2008. Evaluation of QoI fungicide application strategies for managing fungicide resistance and potato early blight epidemics in Wisconsin. Plant Dis. 92:561-568.

Rotem, J. 1994. The genus Alternaria: biology, epidemiology and pathogenicity. APS Press, St. Paul, MN.

Rotem, J., and Feldman, S. 1965. Relation between ratio of yield to foliage and incidence of early blight in potato and tomato. Isr. J. Agric. Res. 15:115-122.

Runno-Paurson, E., Loit, K., Hansen, M., Tein, B., Williams, I. H., and Mand, M. 2015. Early blight destroys potato foliage in the northern Baltic region. Acta Agr Scand B-S P 65:422-432.

Shaner, G., and Finney, R. E. 1977. Effect of nitrogen-fertilization on expression of slow-mildewing resistance in knox wheat. Phytopathology 67:1051-1056.

Shtienberg, D., and Fry, W. E. 1990. Field and computer-simulation evaluation of spray-scheduling methods for control of early and late blight of potato. Phytopathology 80:772-777.

Simko, I., and Haynes, K. G. 2017. Maturity-adjusted resistance of potato (Solanum tuberosum L.) cultivars to Verticillium wilt caused by Verticillium dahliae. Am. J. Potato Res. 94:173-177.

Teng, P. S., and Bissonnette, H. L. 1985. Potato yield losses due to early blight in Minnesota fields, 1981 and 1982. Am. Potato J. 62:619-627. 
Tymon, L. S., Cummings, T. F., and Johnson, D. A. 2016. Pathogenicity and aggressiveness of three Alternaria spp. on potato foliage in the US northwest. Plant Dis. 100:797-801.

Wharton, P., Fairchild, K., Belcher, A., and Wood, E. 2012. First Report of in-vitro boscalid-resistant isolates of Alternaria solani causing early blight of potato in Idaho. Plant Dis. 96:454-455.
Yuen, J. E., and Forbes, G. A. 2009. Estimating the level of susceptibility to Phytophthora infestans in potato genotypes. Phytopathology 99:782786.

Zhang, R. F. 2004. Genetic characterization and mapping of partial resistance to early blight in diploid potato. PhD dissertation. The Pennsylvania State University. 